\title{
Breakdown Measurement of $\mathrm{N} 2 \mathrm{O}$ Mixtures with $\mathrm{CO} 2, \mathrm{~N} 2,02$ in Uniform Electric Fields
}

\section{Journal Article}

\section{Author(s):}

Pachin, Juriy (1); Hösl, Andreas (i); Franck, Christian (1); Kumar, Siddharth; Huiskamp, Tom; Pemen, August J.M.

Publication date:

2021-10

Permanent link:

https://doi.org/10.3929/ethz-b-000515101

Rights / license:

In Copyright - Non-Commercial Use Permitted

Originally published in:

IEEE Transactions on Dielectrics and Electrical Insulation 28(5), https://doi.org/10.1109/TDEI.2021.009591 


\section{(C) 2021 IEEE.}

Personal use of this material is permitted. Permission from IEEE must be obtained for all other uses, in any current or future media, including reprinting/republishing this material for advertising or promotional purposes, creating new collective works, for resale or redistribution to servers or lists, or reuse of any copyrighted component of this work in other works.

The published version is available at DOI: 10.1109/TDEI.2021.009591 


\title{
Breakdown Measurement of $\mathrm{N}_{2} \mathrm{O}$ Mixtures with $\mathrm{CO}_{2}, \mathrm{~N}_{2}, \mathrm{O}_{2}$ in Uniform Electric Fields
}

\author{
Juriy Pachin, Andreas HösI and Christian M. Franck \\ High Voltage Laboratory \\ ETH Zurich, Physikstrasse 3 \\ 8092 Zurich, Switzerland
}

\author{
Siddharth Kumar, Tom Huiskamp and A. J. M. Pemen \\ Electrical Energy Systems \\ Eindhoven University of Technology \\ Eindhoven, 5612 AE, The Netherlands
}

\begin{abstract}
Breakdown strength in uniform electric fields of $\mathrm{N}_{2} \mathrm{O}$ mixtures with $\mathrm{CO}_{2}, \mathrm{~N}_{2}$, and $\mathrm{O}_{2}$ is measured under AC voltage stress, $300 \mathrm{kPa}$ pressure, and electrode separation of $5 \mathrm{~mm}$. The obtained results show the best synergism of $115 \%$ for $\mathrm{N}_{2} \mathrm{O} / \mathrm{CO}_{2} 30 / 70$ mixture. For high electric strength of mixtures a high fraction of $\mathrm{N}_{2} \mathrm{O}$ is beneficial, but is limited by the oxidizing power. Considering this limit a $\mathrm{N}_{2} \mathrm{O} / \mathrm{CO}_{2} 49.1 / 50.9$ mixture can be used with the electric strength $135 \%$ of synthetic air and $45 \%$ of $\mathrm{SF}_{6}$, respectively.
\end{abstract}

Index Terms - nitrous oxide, synergism, alternative gas insulation, electric breakdown

\section{INTRODUCTION}

NITROUS oxide $\left(\mathrm{N}_{2} \mathrm{O}\right)$ and its mixtures have been discussed as an environmentally friendly alternative insulating medium to $\mathrm{SF}_{6}$ in gas insulated switchgears (GIS). $\mathrm{N}_{2} \mathrm{O}$ is a commercially available, non-toxic (LC50 > $500000 \mathrm{ppm}$ ), and non-flammable gas [1]. Anesthetic effects of $\mathrm{N}_{2} \mathrm{O}$ like moderate analgesia start at exposure concentrations of $6 \%$ [2]. The working exposure limit is around $100 \mathrm{ppm}$ [1]. The low boiling point of $-88.5^{\circ} \mathrm{C}$ and low roughness sensitivity would allow higher operating pressures in comparison to $\mathrm{SF}_{6}$. The roughness sensitivity is characterized by the product of gas pressure and protrusion height from which the breakdown field strength starts to drop. It is $43 \mathrm{MPa} \mu \mathrm{m}$ for $\mathrm{N}_{2} \mathrm{O}$ and only $6 \mathrm{MPa} \mu \mathrm{m}$ for $\mathrm{SF}_{6}$, respectively [3]. With a global warming potential (GWP) of 265 to 298 on a 100 year horizon $\left(1.2 \%\right.$ of $\left.\mathrm{SF}_{6}\right)$ [4], $\mathrm{N}_{2} \mathrm{O}$ would significantly reduce the environmental impact of high voltage equipment. The ozone depletion potential (ODP) of $\mathrm{N}_{2} \mathrm{O}$ is estimated to be 0.017 [5]. The total anthropogenic emission of $\mathrm{N}_{2} \mathrm{O}$ is estimated to be in the order of magnitude of 10 million tons per year [6], the total $\mathrm{SF}_{6}$ amount banked in electrical equipment is in the order of magnitude of 0.1 million tons with a leakage rate of $1 \%$ per year [7]. The molar mass of $\mathrm{N}_{2} \mathrm{O}$ is $1 / 3$ of $\mathrm{SF}_{6}$. Consequently the use of $\mathrm{N}_{2} \mathrm{O}$ in electrical equipment would contribute to the total $\mathrm{N}_{2} \mathrm{O}$ emissions with less than 0.001 million tons per year. The gas molecule number density reduced critical electric field strength $(E / N)_{\text {crit }}$ of $\mathrm{N}_{2} \mathrm{O}$ is

Manuscript received on 8 February 2021, in final form 24 July 2021, accepted 6 September2021. Corresponding author: C. M. Franck. reported to be pressure dependent due to three body attachment, which is also a well-known of a number of gases e.g. HFO1234ze(E) [8], $\mathrm{C}_{3} \mathrm{~F}_{6}$, and $\mathrm{C}_{3} \mathrm{~F}_{8}$ [9]. Figure 1 shows the results of several measurements available in literature.

Assuming application pressures of several $100 \mathrm{kPa}$, the electric strength (ES) of $\mathrm{N}_{2} \mathrm{O}$ would be around half that of $\mathrm{SF}_{6}$, and more than 1.6 times that of air [9-12]. However, the use of pure $\mathrm{N}_{2} \mathrm{O}$ in applications is not considered feasible due to its oxidizing power, which is taken to be 0.6 times that of oxygen [15]. The issue is less with combustion - since there is no flammable material within the pressure vessel - but more a matter of material degradation, and rusting.

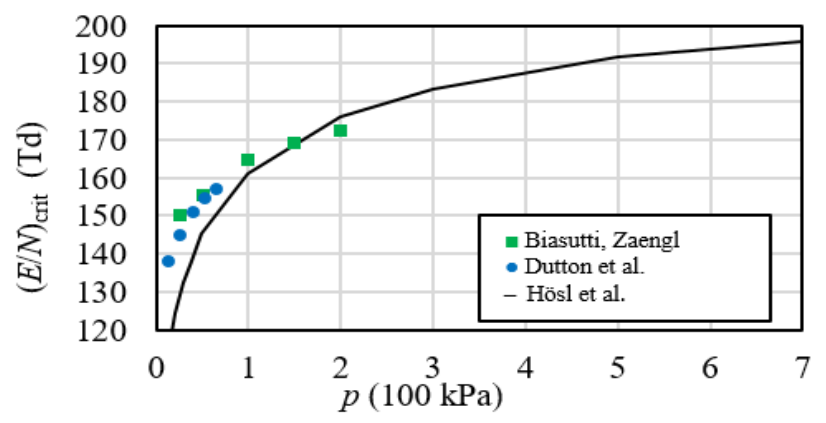

Figure 1. $(E / N)_{\text {crit }}$ of $\mathrm{N}_{2} \mathrm{O}$ for different pressures $p$ and $293 \mathrm{~K}$. Biasutti and Zaengl [9]: calculation from breakdown experiments. Dutton et al [11]: calculation from breakdown experiments. Hösl et al [13]: Calculations based on kinetic model as Bolsig+ simulation based on the cross section set of Dupljanin et al [14] in combination with three-body stabilization. Replotted from [13]. 
To reduce the oxidizing power, $\mathrm{N}_{2} \mathrm{O}$ can be mixed with inert buffer gases such as $\mathrm{N}_{2}$, or $\mathrm{CO}_{2}$, which has the additional advantage of decreasing the environmental impact, by diluting $\mathrm{N}_{2} \mathrm{O}$ and therefore reducing GWP and ODP.

Moreover, recently Hösl et al [13] have discussed a stabilization pass for unstable $\mathrm{NO}^{-}$ions, created by secondary anion processes after dissociative attachment to $\mathrm{N}_{2} \mathrm{O}$. When impacted with an electron, $\mathrm{N}_{2} \mathrm{O}$ readily dissociates into $\mathrm{N}_{2}$ and $\mathrm{O}^{-}$, which is the only relevant attachment channel. Subsequently, $\mathrm{O}^{-}$interacting with a neutral $\mathrm{N}_{2} \mathrm{O}$ may, at high pressures, be stabilized as a $\mathrm{N}_{2} \mathrm{O}_{2}{ }^{-}$anion, which is presumably stable at relevant energies. This stabilization competes with the immediate decay of $\mathrm{N}_{2} \mathrm{O}_{2}{ }^{-}$, resulting in an $\mathrm{NO}^{-}$anion. This anion undergoes rapid electron detachment if not stabilized by further processes. This stabilization can be greatly enhanced by the addition of $\mathrm{O}_{2}$ (Equiaton (1)) and $\mathrm{CO}_{2}$ (Equation (2)), leading to a stable $\mathrm{CO}_{4}^{-}$.

$$
\begin{gathered}
\mathrm{NO}^{-}+\mathrm{O}_{2} \rightarrow \mathrm{NO}+\mathrm{O}_{2}^{-} \\
\mathrm{O}_{2}^{-}+\mathrm{CO}_{2} \rightarrow \mathrm{CO}_{4}^{-}
\end{gathered}
$$

This kind of stabilization might increase the ES of the mixture and might lead to synergism (if ES of the mixed components is better than their linear combination) or even positive synergism (if ES of the mixed components is above that of each of the components) [13]. The beneficial behavior of mixtures of $\mathrm{N}_{2} \mathrm{O}$ with $\mathrm{CO}_{2}, \mathrm{~N}_{2}$, and $\mathrm{O}_{2}$ has been presented by N. Hayakawa et al [16], and by H. Kojima et al [17] for impulse voltages. At $100 \mathrm{kPa}$ pressure, improvements for the 50\%breakdown probability in comparison to pure $\mathrm{N}_{2} \mathrm{O}$ could be achieved up to $35 \%$ for negative, and up to $25 \%$ for positive impulse polarity. W. Pfeiffer and D. Schoen [18] reported for very fast overvoltage stress that 20/80 and 40/60 $\mathrm{N}_{2} \mathrm{O} / \mathrm{N}_{2}$ mixtures can achieve at $700 \mathrm{kPa}$ up to $90 \%$ of $\mathrm{SF}_{6}$ breakdown strength. For $100 \mathrm{kPa}$ however, the performance was only slightly above $\mathrm{N}_{2}$ corresponding to $60 \%$ of $\mathrm{SF}_{6}$. M. Akbar and $\mathrm{N}$. Malik [10] measured a synergy in $\mathrm{N}_{2} \mathrm{O} / \mathrm{CO}_{2}$ for DC voltage. Th. Hammer and T. Kishimoto [19] investigated plasmachemical decomposition of $\mathrm{N}_{2} \mathrm{O} / \mathrm{N}_{2} \quad 40 / 60$ mixture and concluded that no degradation of ES can be expected.

The above listed investigations show that the kinetic processes of $\mathrm{N}_{2} \mathrm{O}$ and its mixtures, and consequently its ES might be pressure dependent. Consequently, low pressure measurements in swarm experiments might not be sufficient to represent the ES at application pressures. Further, there is a lack of data describing the ES of ternary $\mathrm{N}_{2} \mathrm{O}$-mixtures under uniform field stress and slowly increasing voltages.

The goal of the breakdown measurements presented in this publication is to identify if there is a mixture of $\mathrm{N}_{2} \mathrm{O}$ with $\mathrm{CO}_{2}$, $\mathrm{N}_{2}$, and $\mathrm{O}_{2}$ at typical operating pressures with a beneficial ES in comparison to pure $\mathrm{N}_{2} \mathrm{O}$ under uniform field and $\mathrm{AC}$ voltage stress. The article is structure as followed: Section 2 describes the experimental setup, Section 3 the evaluation methods, Section 4 shows the breakdown measurement result, Section 5 discusses the results with focus on synergism and oxidizing power of mixtures, and Section 6 gives a conclusion.

\section{EXPERIMENTAL METHODS}

The experimental breakdown setup of the high voltage laboratory of ETH Zurich, previously described in [20], is shown in Figure 2. For the AC high-voltage circuit, standard components of the Messwandler-Bau Bamberg (MWB) construction kit are used. The AC voltage is provided by a control unit containing a frequency converter with a filter [21]. The control unit can automatically execute the experimental sequence with settings of maximal voltage, voltage rate of rise, number of repetitions, and waiting time between consecutive voltage applications. A breakdown detection feedback loop turns off the voltage within $30 \mathrm{~ms}$ to limit the discharge energy and decrease the stress on the gas under investigation and on the electrode surface. In addition, the energy dissipated in the discharge spark is limited by two series-connected $50 \mathrm{k} \Omega$ resistors. The voltage is measured by a capacitive divider and a MU17 HIGHVOLT unit saving the sine voltage peak before the breakdown. The overall voltage measurement accuracy is better than $2 \%$. In order to reduce the statistical time lag, the AC voltage rate of rise before breakdown is $0.1 \mathrm{kV} / \mathrm{s}$. To have a reasonable low experimental time, the rate of rise is $2 \mathrm{kV} / \mathrm{s}$ up to $80 \%$ of the estimated breakdown voltage.

The gas is stressed with a uniform electric field created by two plane electrodes with a Rogowski shaped edge profile. The plane electrodes provide a large stressed volume in comparison to sphere arrangements and reduce the statistical time lag this way. The stainless steel (EN 1.4460) electrodes have a total diameter of $80 \mathrm{~mm}$ with a flat area dimeter of $40 \mathrm{~mm}$ and ensure a uniform field up to $15 \mathrm{~mm}$ separation distance.

The electrode finish is polished with fine sandpaper. Measurements with a contact profilometer (JENOPTIK HOMMEL-ETAMIC TURBO WAVE) delivered a roughness of $R_{\mathrm{t}}=1.3 \mu \mathrm{m}$, with $R_{\mathrm{t}}$ defined as difference between the highest peak and deepest valley measured on a path of $4.8 \mathrm{~mm}$ along the electrode surface. We estimate a more conservative roughness of $R_{\mathrm{t}}=3 \mu \mathrm{m}$.

For the present investigations an electrode separation of $5 \mathrm{~mm}$ is used. The electrodes are supported by a polypropylene (PP) tube placed inside the pressure vessel to decouple them mechanically from the outer vessel and ensure a pressureindependent separation. The temperature-dependent change of the electrode separation, due to the thermal expansion of the PPtube, was measured for a temperature range from $20^{\circ} \mathrm{C}$ to $27^{\circ} \mathrm{C}$. A linear approximation delivers a separation change of $48.37 \mu \mathrm{m} / \mathrm{K}$, which is considered in the data evaluation for $E / N$.

The electrodes are aligned parallel by three bolts connecting the upper electrode to a holding plate. The necessary counterforce is generated by stiff springs around the bolts. The separation and the alignment is set using gauge blocks available in $1000 \mu \mathrm{m}, 100 \mu \mathrm{m}, 10 \mu \mathrm{m}$, and $1 \mu \mathrm{m}$ step size. Trials with using different step sizes and fine electrodes readjustment showed a separation accuracy estimated to be $\pm 80 \mu \mathrm{m}$, and the parallelism $\pm 5 \mu \mathrm{m}$. The good parallelism and uniform electric field distribution are confirmed by the uniform distribution of breakdown spark roots over the flat electrode area after the 
experiments. The field uniformity at the flat area, where the breakdown sparks took place, is considered to be $100 \%$. As if a field enhancement would appear on Rogowki-electrodes, then it would be around the edges leading to spark root concertation in this region.

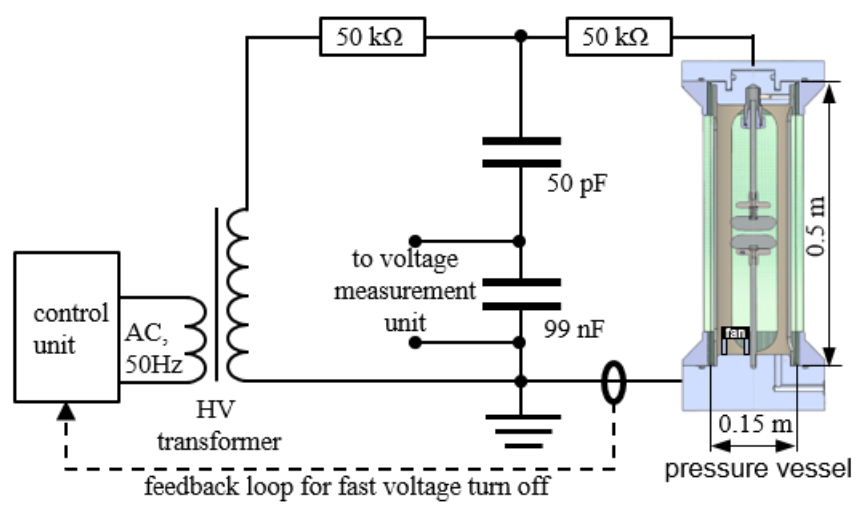

Figure 2. Schematics of the experimental setup with breakdown circuit and pressure vessel.

The gases are filled and mixed directly in the experimental vessel which is made of glass-fiber reinforced epoxy with 11.5 L volume, designed for a maximal pressure of $900 \mathrm{kPa}$. A good mixing of components is ensured by a fan inside the vessel. The fan with $2 \mathrm{~cm}$ stilts placed on the floor of the vessel, creates a flow direction from the bottom to the top. The mixing time was $>20 \mathrm{~min}$. The indicated percentage of mixtures is related to their partial pressures during filling. Pressure and temperature are measured by a WIKA CPG1500 sensor with a pressure accuracy $\leq 0.6 \mathrm{kPa} \quad(6 \mathrm{mbar})$ and estimated temperature accuracy $\leq 1 \mathrm{~K}$.

In each gas mixture 50 to 250 breakdowns are performed. For each breakdown pressure and temperature is recorded. The time between two consecutive breakdowns is around $4 \mathrm{~min}$.

\section{EVALUATION METHODS}

\subsection{PERCENTILES CALCULATION}

A breakdown is a statistical process. For a uniform field at least two criteria have to be fulfilled: the electric field strength has to be high enough to fulfill the ignition criterion for Townsend or streamer mechanism, and a seed electron has to be available to start the breakdown process. The distribution of breakdown values is not necessarily normal, so a binominal distribution is used for the evaluation. The results are presented as median with 84.13 and 15.87 percentiles with $75 \%$ of confidence according to [22]. The corresponding values can be calculated according to Equation (3) ordering the breakdown voltages in an increasing order to a list with samples $x_{i}$, $i=1 \ldots n$, with total breakdown number $n$, and $1 \leq m \leq n / 2$, where $m$ is any integer. $P_{\text {prc }}$ is the point below which a certain percentage of the measured points lie, prc is a certain percentile of distribution. $P\{\}$ is the confidence of the percentile. $k$ is a running number for the sum calculation. The binomial coefficient is calculated with Equation (4). For the evaluation we use $P\left\{x_{m} \leq P_{15.87}\right\}=0.75$. The example for different sample sizes are shown in Table 1. The example of breakdown values sorted to increasing order with highlighted percentiles is shown in Figure 3.

$$
\begin{aligned}
& P\left\{x_{m} \leq P_{p r c}\right\}= \\
& P\left\{x_{n-m+1}>P_{1-p r c}\right\}= \\
& 1-\sum_{k=0}^{m-1}\left(\begin{array}{l}
n \\
k
\end{array}\right) \operatorname{prc}^{k}(1-p r c)^{n-k} \\
& \left(\begin{array}{l}
n \\
k
\end{array}\right)=\frac{n !}{k ! \cdot(n-k) !} .
\end{aligned}
$$

For a normal distribution, the median will correspond to the mean, and the 84.13 and 15.87 percentiles to median plus and minus the standard deviation, respectively.

Table 1. Percentile values $i$ for different sample sizes $n$.

\begin{tabular}{c|c|c}
\hline \multirow{2}{*}{$\begin{array}{c}\text { Total } \\
\text { breakdown } \\
\text { number } n\end{array}$} & \multicolumn{2}{|c}{$\begin{array}{c}\text { value } i \text { of percentiles } \\
\text { for } 75 \% \text { confidence } P\{\}\end{array}$} \\
\cline { 2 - 3 } & $\begin{array}{c}\text { prc } \\
15.87 \%\end{array}$ & $\begin{array}{c}1-p r c \\
84.13 \%\end{array}$ \\
\hline 5 & - & - \\
10 & 1 & 10 \\
20 & 2 & 29 \\
30 & 3 & 28 \\
50 & 6 & 45 \\
100 & 13 & 88 \\
150 & 16 & 135 \\
200 & 28 & 173 \\
250 & 36 & 215 \\
\hline
\end{tabular}

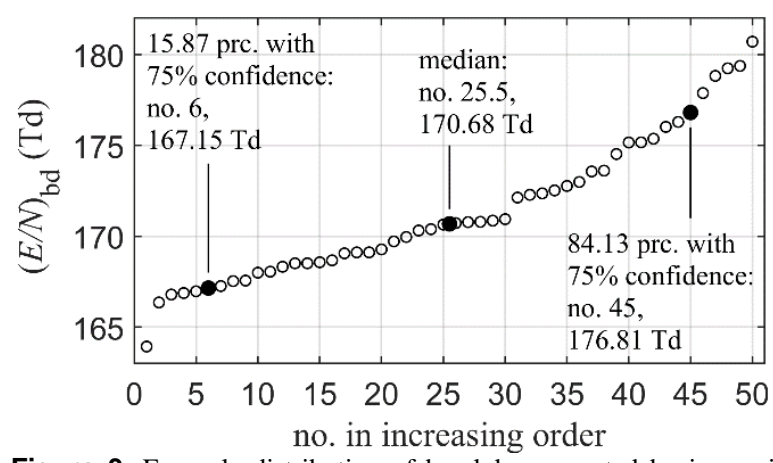

Figure 3. Example distribution of breakdowns sorted by increasing values with indications of median and confidence intervals for $50 / 50 \mathrm{~N}_{2} \mathrm{O} / \mathrm{CO}_{2}$.

\subsection{E/N CALCULATION}

$(E / N)_{\text {crit }}$, defined as $E / N$ value where the corresponding effective ionization rate is zero, can be obtained with swarm experiments under low pressures (typically $\ll 10 \mathrm{kPa}$ ). Measurements at operating pressures in breakdown experiments with uniform field stress, deliver the gas molecule number density reduced breakdown field strength $(E / N)_{\text {bd }}$, which is above $(E / N)_{\text {crit. }}$ With increasing product of gas pressure and electrode separation $p s,(E / N)_{\text {bd }}$ converges to $(E / N)_{\text {crit. }}$ For high $p s$ values $(E / N)_{\mathrm{bd}} \approx(E / N)_{\text {crit }}$ is valid [3]. $(E / N)_{\mathrm{bd}}$ enables to compare the breakdown voltages $U_{\mathrm{bd}}$ in uniform field stress under different experimental conditions like electrode separation $s$, pressure $p$ (in $\mathrm{Pa}$ ) and temperature $T$ (in $\mathrm{K}$ ). Assuming the ideal gas law, $(E / N)_{\text {bd }}$ can be calculated according 
to Equation (5). Its unit is Townsend $\left(1 \mathrm{Td}=10^{-21} \cdot \mathrm{V} \cdot \mathrm{m}^{2}\right)$. $\mathrm{k}_{\mathrm{B}}$ is the Boltzmann constant.

$$
\left(\frac{E}{N}\right)_{\mathrm{bd}}=\frac{U_{\mathrm{bd}} / s}{p /\left(\mathrm{k}_{\mathrm{B}} \cdot T\right)}
$$

The temperature-dependent change of the electrode separation is also considered for each breakdown with Equation (6), taking into account the separation $s_{\text {init }}$ and temperature $T_{\text {init }}$ during separation setting.

$$
s=s_{\text {init }}+48.37 \frac{\mu \mathrm{m}}{\mathrm{K}} \cdot\left(T-T_{\text {init }}\right)
$$

The overall accuracy of $(E / N)$ bd value is supposed to be better than $7 \%$, which is due to the uncertainties of separation setting, and measurements of temperature, pressure, and voltage.

\subsection{SYNERGISM CALCULATION}

A possible beneficial effect of using a gas mixture is that its $(E / N)_{\text {cirt }}$ and consequently $(E / N)_{\text {bd }}$ may exceed the linear combination of the partial components weighted by their molar fraction $(\mathrm{mol} \%)$. The synergism coefficient $(S C)$ can be calculated according to Equation (7) for $n$ components. If $S C>100 \%$, we can talk about synergism. If in addition $(E / N)_{\mathrm{bd} \text {,mixture }}>(E / N)_{\mathrm{bd}, \text { comp } \mathrm{x}}$ is valid for all components $x$ in pure state, we can talk about positive synergism [23].

$$
S C=\frac{(E / N)_{\mathrm{bd}, \text { mixture }}}{\sum_{x=1}^{n}\left[\operatorname{mol}_{\operatorname{compx}} \cdot(E / N)_{\mathrm{bd}, \mathrm{compx}}\right]}
$$

\subsection{OXIDIZING POWER CALCULATION}

According to EN-ISO-10156 the oxidizing power $(O P)$ of a gas mixture is given in relation to pure oxygen. $O P$ of $\mathrm{O}_{2}$ is consequently $100 \%$. A gas mixture is classified as oxidizing if its $O P$ is above $23.5 \%$. $O P$ can be calculated as molar fraction (mol\%) weighted with ratio of oxygen $(O E)$ and nitrogen equivalencies $(N E)$ of the mixed components. $O E$ of $\mathrm{O}_{2}$ is 1.0, $O E$ of $\mathrm{N}_{2} \mathrm{O}$ is 0.6. $N E$ of $\mathrm{N}_{2}$ is 1.0 and $N E$ of $\mathrm{CO}_{2}$ is 1.5. With these data the $O P$ of the investigated mixtures can be calculated with Equation (8).

$$
\begin{aligned}
& O P=\frac{\sum\left[m o l \%_{\text {oxidizing comp x }} \cdot O E_{\text {oxidizing comp x }}\right]}{\sum m o l \%_{\text {oxidizing comp x }}+\sum\left[m o l \%_{\text {inert comp x }} \cdot N E_{\text {inert comp x }}\right]} \\
& =\frac{m o l \%_{\mathrm{N}_{2} \mathrm{O}} \cdot 0.6+m o l \%_{\mathrm{O}_{2}} \cdot 1.0}{m o l \%_{\mathrm{N}_{2} \mathrm{O}}+m o l \%_{\mathrm{O}_{2}}+m o l \%_{\mathrm{CO}_{2}} \cdot 1.5+m o l \%_{\mathrm{N}_{2}} \cdot 1.0}
\end{aligned}
$$

\section{RESULTS}

In this manuscript four sets of experiments were conducted. First, breakdown experiments were performed on individual gases such as $\mathrm{CO}_{2}$ and $\mathrm{N}_{2} \mathrm{O}$. Then to analyze the effect of gas mixtures as mentioned in earlier sections, breakdown experiments were conducted on binary mixtures of $\mathrm{N}_{2} \mathrm{O}$ with $\mathrm{N}_{2}, \mathrm{CO}_{2}$, and $\mathrm{O}_{2}$ at $300 \mathrm{kPa}$ with an electrode separation of $5 \mathrm{~mm}$. Similarly, another set of measurements were performed on ternary mixtures of $\mathrm{N}_{2} \mathrm{O} / \mathrm{CO}_{2} / \mathrm{O}_{2}$, and $\mathrm{N}_{2} \mathrm{O} / \mathrm{CO}_{2} / \mathrm{N}_{2}$. Finally, the experiments were expanded to quaternary mixtures of $\mathrm{N}_{2} \mathrm{O} / \mathrm{CO}_{2} / \mathrm{N}_{2} / \mathrm{O}_{2}$. The results of the various experiments are plotted as described in the following paragraphs.

Figures 4 to 8 show the breakdown results as median with 15.87 and 84.13 percentiles with $75 \%$ of confidence, for the electrode separation of $5 \mathrm{~mm}$.

Figure 4 shows a pressure scan for pure $\mathrm{N}_{2} \mathrm{O}, \mathrm{CO}_{2}$, and a $\mathrm{N}_{2} \mathrm{O} / \mathrm{CO}_{2} 38 / 62$ mixture. This mixture has a $\mathrm{N}_{2} \mathrm{O}$ fraction around the maximal possible amounts for mixing with $\mathrm{N}_{2}$ and $\mathrm{CO}_{2}$ to have same $O P$ as air (compare discussion in section 5). Figure $4 \mathrm{a}$ shows the breakdown voltages $U_{\text {bd }}$ and Figure $4 \mathrm{~b}$ the same values represented as $(E / N)_{\text {bd }}$. It can be observed that $\mathrm{N}_{2} \mathrm{O}$ has a breakdown strength of 1.75 times as that of $\mathrm{CO}_{2}$.
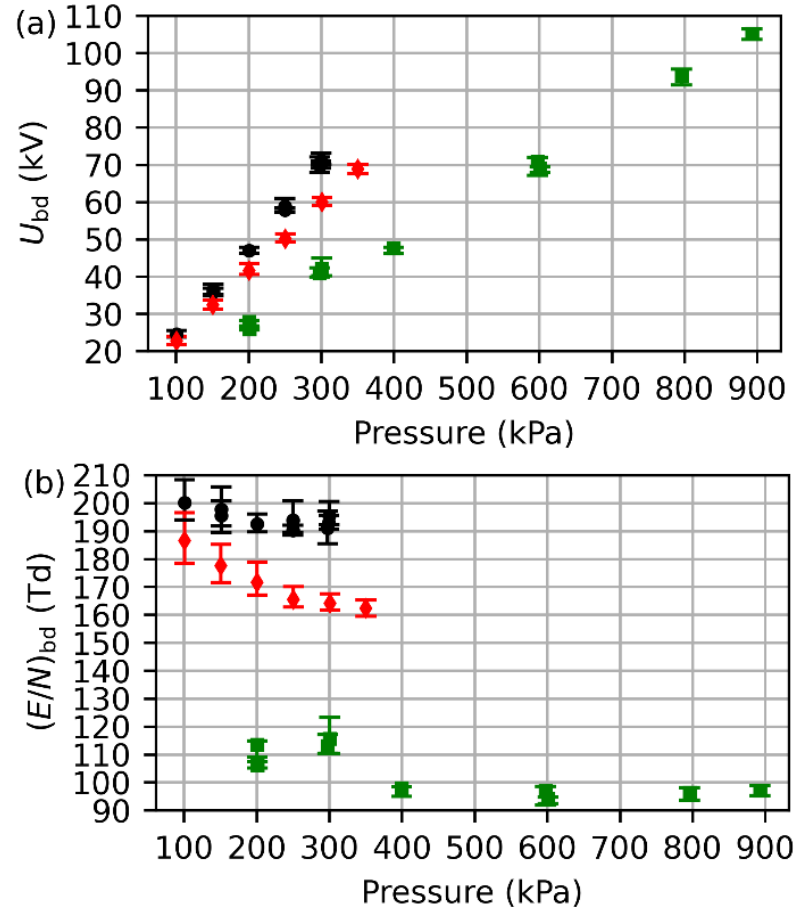

$\mathrm{N}_{2} \mathrm{O}$

$\mathrm{CO}_{2}$

$38 \% \mathrm{~N}_{2} \mathrm{O} / 62 \% \mathrm{CO}_{2}$

Figure 4. AC peak (a) breakdown voltage $U_{\mathrm{bd}}$ and (b) gas molecule number density reduced breakdown field strength $(E / N)_{\text {bd }}$ of $\mathrm{N}_{2} \mathrm{O}, \mathrm{CO}_{2}$, and a $\mathrm{N}_{2} \mathrm{O} / \mathrm{CO}_{2}$ for $5 \mathrm{~mm}$ separation and different pressures. 


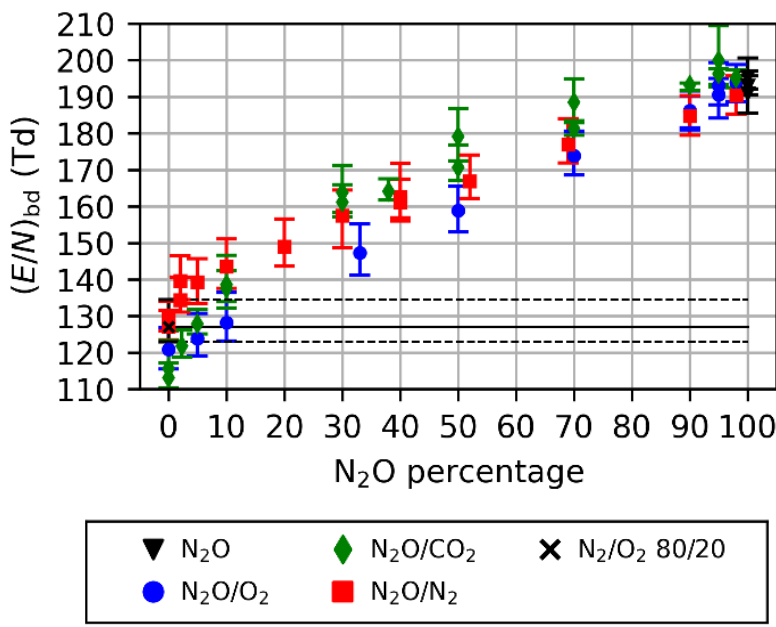

Figure 5. AC peak gas molecule number density reduced breakdown field strength $(E / N)_{\text {bd }}$ of binary mixtures of $\mathrm{N}_{2} \mathrm{O}$ with $\mathrm{N}_{2}, \mathrm{CO}_{2}$, and $\mathrm{O}_{2}$. Electrode separation $5 \mathrm{~mm}$, gas pressure $300 \mathrm{kPa}$. Black lines indicate breakdown field strength of $\mathrm{N}_{2} / \mathrm{O}_{2} 80 / 20$. Black solid line: median, dashed lines: percentiles.

Figure 5 shows results of the breakdown experiment performed on binary mixtures of $\mathrm{N}_{2} \mathrm{O}$ with $\mathrm{N}_{2}, \mathrm{CO}_{2}$, and $\mathrm{O}_{2}$ at $300 \mathrm{kPa}$. Similarly, Figures 6 shows the results of breakdown experiments on ternary mixtures at $300 \mathrm{kPa}$ of $\mathrm{N}_{2} \mathrm{O} / \mathrm{CO}_{2} / \mathrm{O}_{2}$, and Figure $7 \mathrm{~N}_{2} \mathrm{O} / \mathrm{CO}_{2} / \mathrm{N}_{2}$. Figure 5 to 7 show an increasing trend in breakdown strength with increase in $\mathrm{N}_{2} \mathrm{O}$ content in the mixtures.

Figure 8 shows $(E / N)_{\text {bd }}$ values of some quaternary mixtures with mixing ratios according to [17].

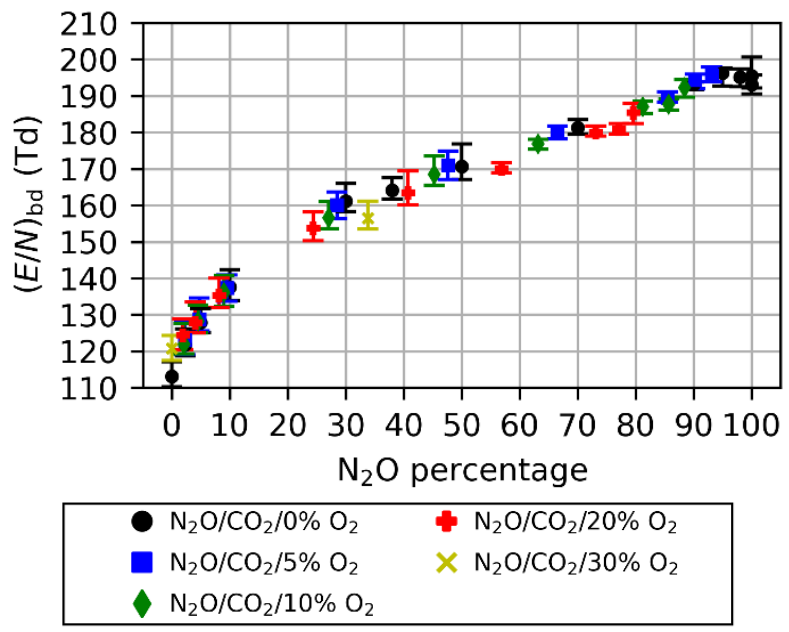

Figure 6. AC peak gas molecule number density reduced breakdown field strength $(E / N)_{\text {bd }}$ of ternary $\mathrm{N}_{2} \mathrm{O} / \mathrm{CO}_{2} / \mathrm{O}_{2}$ mixtures. Electrode separation $5 \mathrm{~mm}$, gas pressure $300 \mathrm{kPa}$.

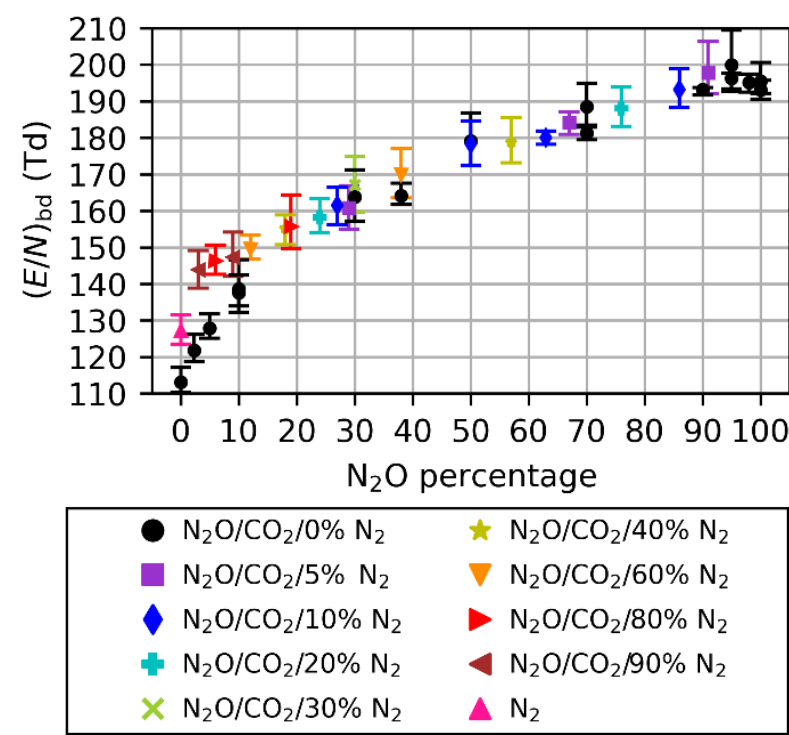

Figure 7. AC peak gas molecule number density reduced breakdown field strength $(E / N)_{\text {bd }}$ of ternary $\mathrm{N}_{2} \mathrm{O} / \mathrm{CO}_{2} / \mathrm{N}_{2}$ mixtures. Electrode separation $5 \mathrm{~mm}$, gas pressure $300 \mathrm{kPa}$.

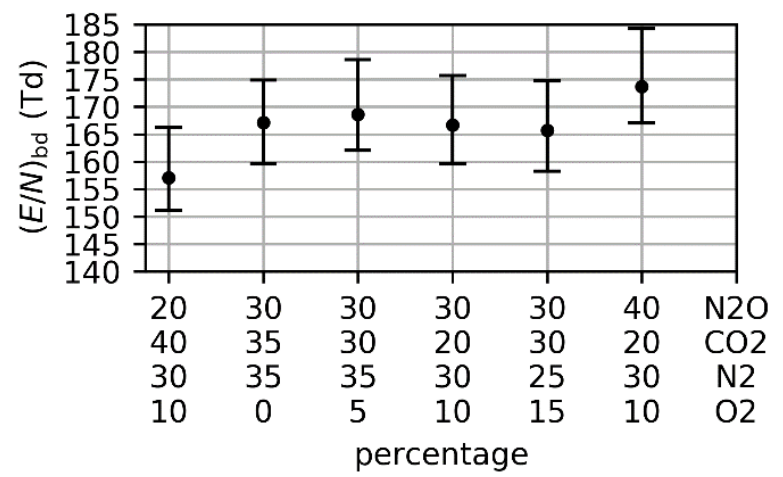

Figure 8. AC peak gas molecule number density reduced breakdown field strength $(E / N)_{\text {bd }}$ of quaternary $\mathrm{N}_{2} \mathrm{O} / \mathrm{CO}_{2} / \mathrm{N}_{2} / \mathrm{O}_{2}$ mixtures. Electrode separation $5 \mathrm{~mm}$, gas pressure $300 \mathrm{kPa}$. 


\section{DISCUSSION}

In this section, the results of the breakdown experiments are compared with similar studies available in literature. Furthermore, the synergistic effects of the gas mixtures along with its oxidizing power for practical applications is discussed.

\subsection{COMPARISON OF ELECTRIC STRENGTH WITH LITERATURE}

For the discussion the data are compared in Figure 9 with data available in literature. Figure $9 \mathrm{~b}$ shows buffer gases measured by P. Haefliger [20, 24] under similar experimental conditions, but with sandblasted electrodes. While the difference between the 15.87 and 84.13 percentiles of $\mathrm{P}$. Haefliger is below $5 \mathrm{Td}$ (not visible in the figure), the results of the present study show a scattering of around $10 \mathrm{Td}$. The median values are around $10 \mathrm{Td}$ above Haefliger's. This might be related to the increased statistical time lag due to the polished electrodes and the lower electron emission rate from the cathode surface in comparison to the sandblasted version. But also a relation to measurement accuracy of voltage, pressure, temperature and electrode distance cannot be excluded. We assume the 15.87 percentile to be more significant than the median to characterize the ES in the present study. This value is used to calculate synergism.

Figure 9a shows the comparison of breakdown measurements in pure $\mathrm{N}_{2} \mathrm{O}$. A pressure dependence of ES of $\mathrm{N}_{2} \mathrm{O}$ cannot be observed. It has to be taken into account that in the current study the measurements were performed with changing the pressure only, while in literature in addition to pressure also the spacing has been changed to have the same $p s$ under different pressures. In the current study the $(E / N)_{\text {bd }}$ decrease due to increasing $p s$ may be more dominant than its increase with pressure. The measured ES between 185 and $190 \mathrm{Td}$ are slightly above the literature values at similar pressure, but in the range of the estimated experimental error.

The synergism of $\mathrm{N}_{2} \mathrm{O} / \mathrm{CO}_{2}$ mixtures agrees with [10] and [16] as shown in Figure 10a. There is no further synergism increase with admixture of oxygen as assumed in [13] and reported for $100 \mathrm{kPa}$ in [16]. A possible reason might be the increased pressure of $300 \mathrm{kPa}$ leading to saturation of some ion kinetic processes, notably the primary three-body stabilization of $\mathrm{O}^{-}$, drying out the $\mathrm{NO}^{-}$path altogether.
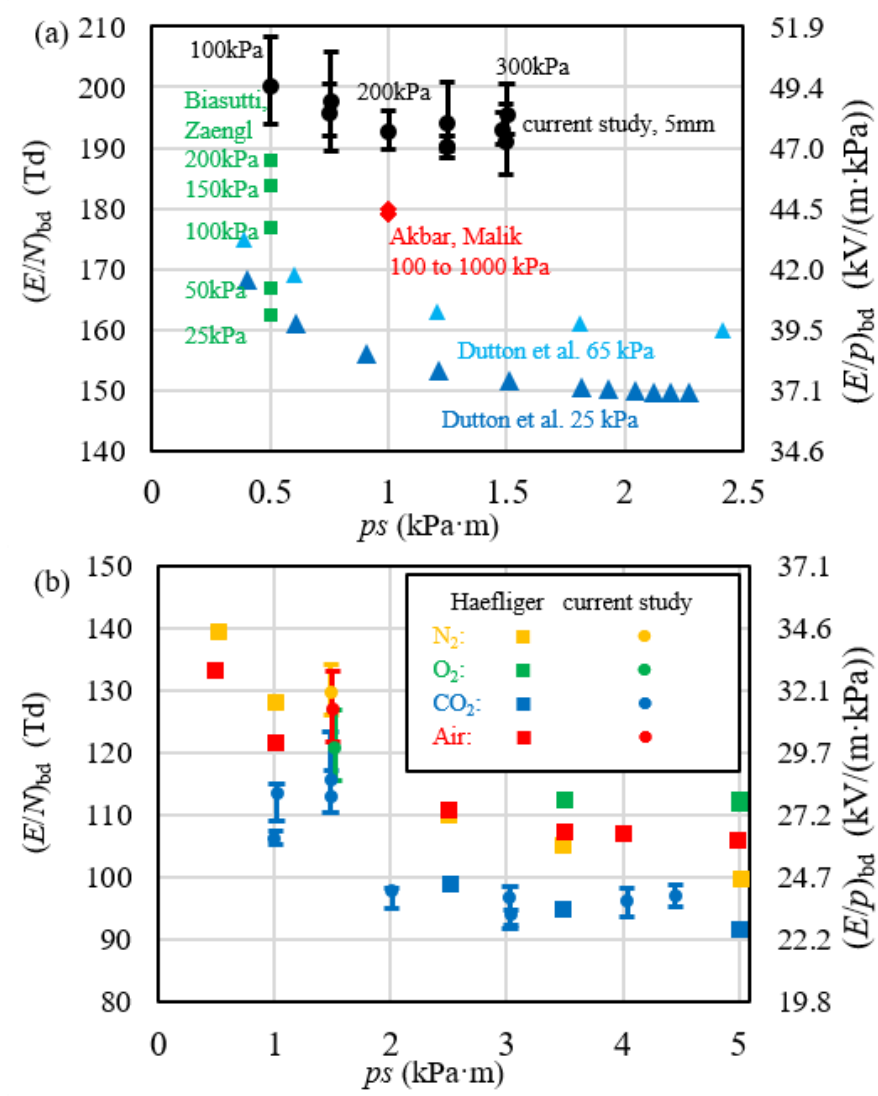

Figure 9. $(E / N)_{\text {bd }}$ and $(E / p)_{\text {bd }}$ at $20^{\circ} \mathrm{C}$ for (a) $\mathrm{N}_{2} \mathrm{O}$ and (b) buffer gases. Akbar and Malik [10]: polished plane electrodes out of steel with Harrison profile and distance from $2 \mathrm{~mm}$ to $20 \mathrm{~mm}$. Biasutti and Zaengl [9]: polished plane electrodes out of steel with Rogowski profile and distance up to $20 \mathrm{~mm}$. Dutton et al [11]: silver plated plane electrodes with Bruce profile. Haefliger [20, 24]: similar electrode geometry as in current study but sandblasted.

The good performance with admixtures of $\mathrm{N}_{2}$, and for quaternary mixtures measured in $[16,17]$ for $100 \mathrm{kPa}$ with impulse voltage, is not observed in the current study with $300 \mathrm{kPa}$ and AC voltage stress.

As was shown in $[20,24]$ it might be not sufficient to compare gas mixtures at only one $p s$ value as $(E / N)_{\text {bd }}$ decrease with increasing $p s$. The resulting Paschen's curves might intersect. So a gas mixture which seems to be slightly beneficial at low $p s$ values, might be unfavorable at higher $p s$ values. This behavior may be significant for gases with small deviations in $(E / N)_{\text {bd }}$ like for air and mixtures with small $\mathrm{N}_{2} \mathrm{O}$ fraction. For significant large difference in $(E / N)$ bd of $20 \mathrm{Td}$ and more, like between air and mixtures with more than $20 \% \quad \mathrm{~N}_{2} \mathrm{O}$ this phenomena should not play a role.

Further it has also to be considered that for gases with pressure dependent $(E / N)_{\text {crit }}$ due to three body attachment, swarm parameter measurements at low pressures are not sufficient for the characterization of the gas. In addition measurements at real application pressures, or physical models for extrapolation toward higher pressures are necessary. 


\subsection{SYNERGISM}

For all investigated mixtures no strong synergism can be observed (Figures 10a to 12a ). The best synergism values of around $115 \%$ are observed for $\mathrm{N}_{2} \mathrm{O} / \mathrm{CO}_{2}$ fractions around $30 \%$. For $\mathrm{N}_{2} \mathrm{O} / \mathrm{N}_{2}$ the synergism is poor by reaching $105 \%$. For $\mathrm{N}_{2} \mathrm{O} / \mathrm{O}_{2}$ no synergism can be observed.

The performance of ternary $\mathrm{N}_{2} \mathrm{O} / \mathrm{CO}_{2} / \mathrm{O}_{2}$ as well as of $\mathrm{N}_{2} \mathrm{O} / \mathrm{CO}_{2} / \mathrm{N}_{2}$ mixtures is similar to $\mathrm{N}_{2} \mathrm{O} / \mathrm{CO}_{2}$, and decreases with the dominance of $\mathrm{O}_{2}$ and $\mathrm{N}_{2}$ fraction, respectively. The performance of quaternary $\mathrm{N}_{2} \mathrm{O} / \mathrm{CO}_{2} / \mathrm{N}_{2} / \mathrm{O}_{2}$ mixtures seems to depend mainly on $\mathrm{N}_{2} \mathrm{O}$ fraction and not on the variation of other components.
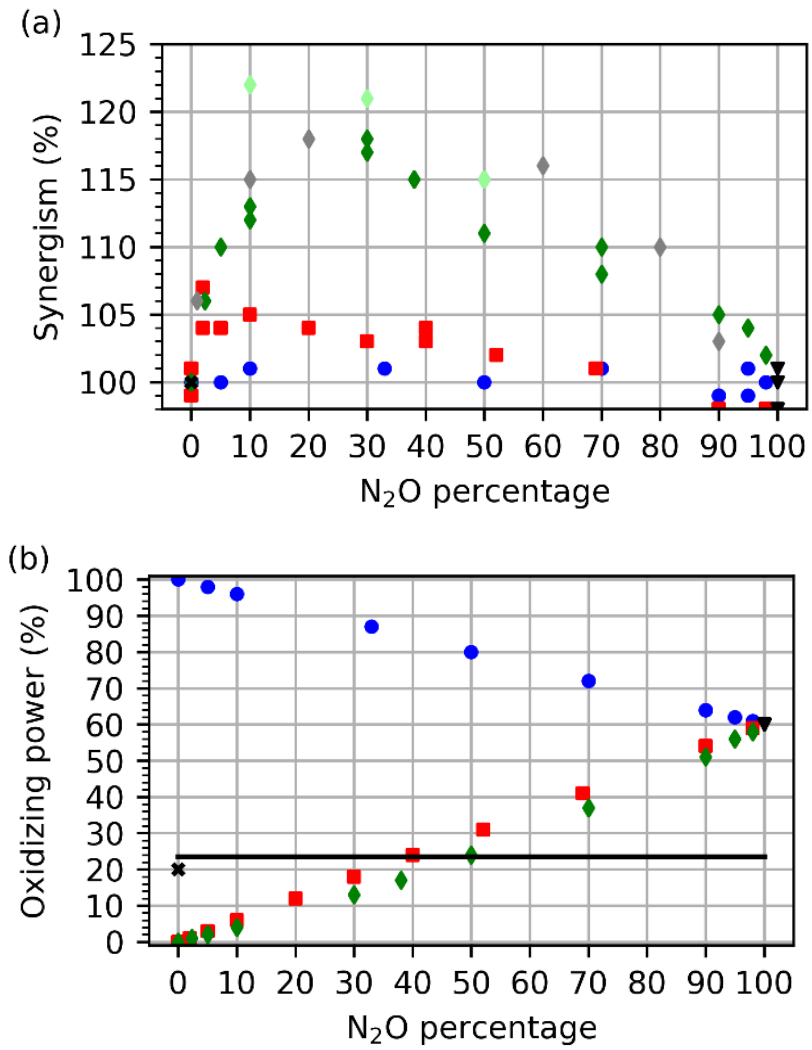

\begin{tabular}{ll|}
$\nabla \mathrm{N}_{2} \mathrm{O}$ & $\times \mathrm{N}_{2} / \mathrm{O}_{2} 80 / 20$ \\
$\mathrm{~N}_{2} \mathrm{O} / \mathrm{O}_{2}$ & $\mathrm{~N}_{2} \mathrm{O} / \mathrm{CO}_{2}$, Akbar, Malik \\
$\mathrm{N}_{2} \mathrm{O} / \mathrm{CO}_{2}$ & $\mathrm{~N}_{2} \mathrm{O} / \mathrm{CO}_{2}$, Hayakawa et al. \\
& \\
\hline $\mathrm{N}_{2} \mathrm{O} / \mathrm{N}_{2}$ & \\
\hline
\end{tabular}

Figure 10. Comparison of (a) synergism and (b) oxidizing power of binary mixtures. Akbar and Malik [10]: polished plane electrodes with Harrison profile, 30 to $100 \mathrm{kPa}$, DC. Hayakawa et al [16]: polished sphere (diameter $50 \mathrm{~mm}$ )-plane with separation of $10 \mathrm{~mm}, 100 \mathrm{kPa}, \mathrm{AC}$. Present study: Planeplane Rogowski profiled electrodes, separation $5 \mathrm{~mm}, 300 \mathrm{kPa}$, AC. Black line indicates the oxidizing power limit of $23.5 \%$.

\subsection{OXIDIZING POWER}

The oxidizing power sets a limit of $\mathrm{N}_{2} \mathrm{O}$ and $\mathrm{O}_{2}$ fractions for applications in equipment. The limit of $23.5 \%$ is indicated in Figures $10 \mathrm{~b}$ to $12 \mathrm{~b}$ by the black solid line. The use of pure $\mathrm{N}_{2} \mathrm{O}$ as well as its mixtures with $\mathrm{O}_{2}$ is not possible, while the addition of $\mathrm{N}_{2}$ or $\mathrm{CO}_{2}$ creates applicable mixtures. The $O P$ of air $(20 \%$ for $\mathrm{O}_{2} / \mathrm{N}_{2} 20 / 80$ ) can be reached with $\mathrm{N}_{2} \mathrm{O} / \mathrm{N}_{2} 33.3 / 66.7$ and $\mathrm{N}_{2} \mathrm{O} / \mathrm{CO}_{2} 42.8 / 57.2$ mixtures. According to this study, the ES of these mixtures would be $12 \%$ and $32 \%$ superior to synthetic air, respectively. The fraction of $\mathrm{N}_{2} \mathrm{O}$ can be increased even further to $\mathrm{N}_{2} \mathrm{O} / \mathrm{CO}_{2} 49.1 / 50.9$ by going to the $23.5 \%$ OP limit.
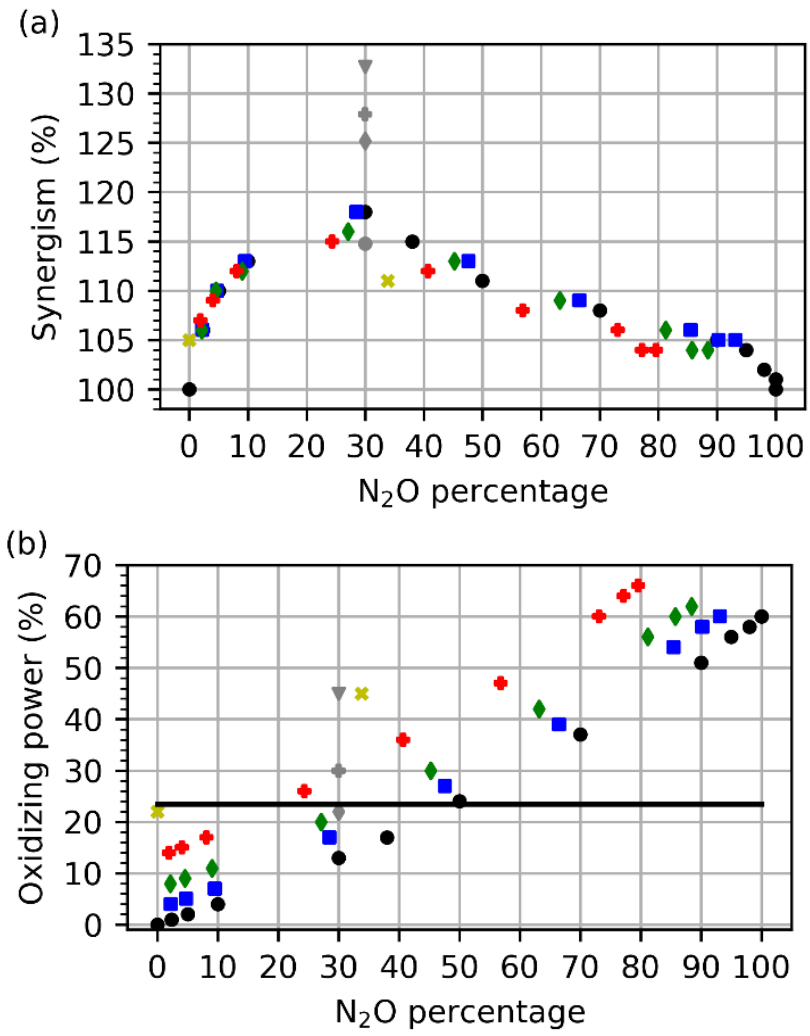

\begin{tabular}{|ll|}
$\mathrm{N}_{2} \mathrm{O} / \mathrm{CO}_{2} / 0 \% \mathrm{O}_{2}$ & $\mathrm{~N}_{2} \mathrm{O} / \mathrm{CO}_{2} / 0 \% \mathrm{O}_{2}$, Hay. \\
$\mathrm{N}_{2} \mathrm{O} / \mathrm{CO}_{2} / 5 \% \mathrm{O}_{2}$ & $\mathrm{~N}_{2} \mathrm{O} / \mathrm{CO}_{2} / 10 \% \mathrm{O}_{2}$, Hay. \\
$\mathrm{N}_{2} \mathrm{O} / \mathrm{CO}_{2} / 10 \% \mathrm{O}_{2}$ & $\mathrm{~N}_{2} \mathrm{O} / \mathrm{CO}_{2} / 20 \% \mathrm{O}_{2}$, Hay. \\
$\mathrm{N}_{2} \mathrm{O} / \mathrm{CO}_{2} / 20 \% \mathrm{O}_{2}$ & $\nabla \mathrm{N}_{2} \mathrm{O} / \mathrm{CO}_{2} / 35 \% \mathrm{O}_{2}, \mathrm{Hay}$ \\
$\times \mathrm{N}_{2} \mathrm{O} / \mathrm{CO}_{2} / 30 \% \mathrm{O}_{2}$ & \\
\hline
\end{tabular}

Figure 11. Comparison of (a) synergism and (b) oxidizing power of ternary $\mathrm{N}_{2} \mathrm{O} / \mathrm{CO}_{2} / \mathrm{O}_{2}$ mixtures. Hay. [16]: polished sphere (diameter $50 \mathrm{~mm}$ )-plane with separation of $10 \mathrm{~mm}, 100 \mathrm{kPa}$, AC. Present study: Plane-plane Rogowski profiled electrodes, separation $5 \mathrm{~mm}, 300 \mathrm{kPa}, \mathrm{AC}$. Black line indicates the oxidizing power limit of $23.5 \%$. 
This is the author's version of an article has been published in this journal. Changes were made to this version by the publisher prior to publication.

(a)

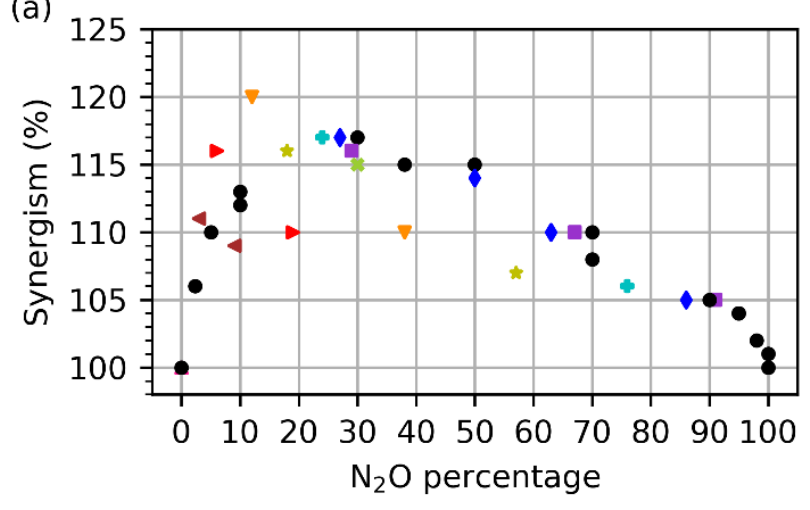

(b)

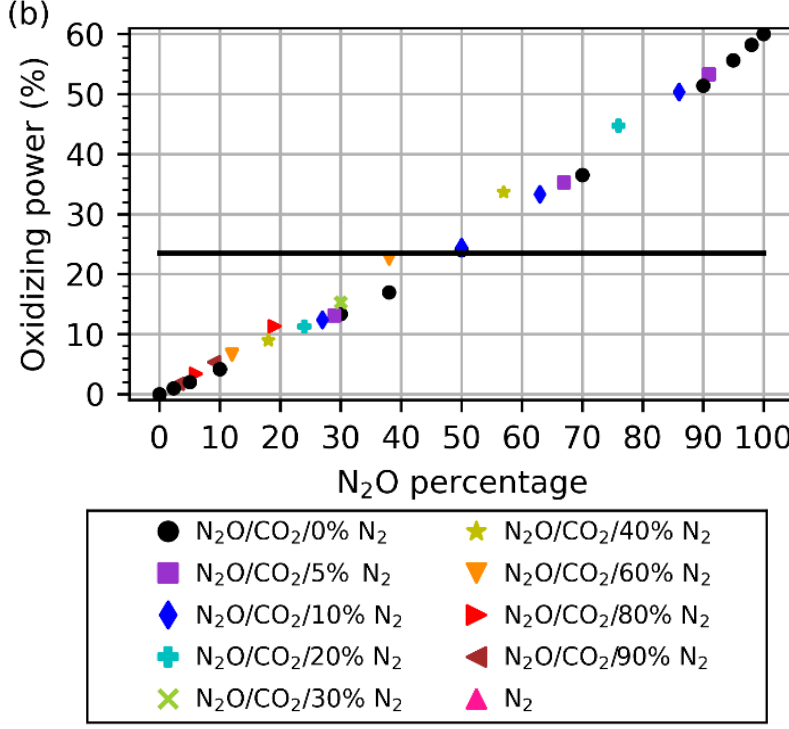

Figure 12. Comparison of (a) synergism and (b) oxidizing power of ternary $\mathrm{N}_{2} \mathrm{O} / \mathrm{CO}_{2} / \mathrm{N}_{2}$ mixtures. Present study: Plane-plane Rogowski profiled electrodes, separation $5 \mathrm{~mm}, 300 \mathrm{kPa}$, AC. Black line indicates the oxidizing power limit of $23.5 \%$.

\section{CONCLUSIONS}

The ES of mixtures of $\mathrm{N}_{2} \mathrm{O}$ with $\mathrm{CO}_{2}, \mathrm{~N}_{2}$, and $\mathrm{O}_{2}$ has been investigated under uniform electric field stress with $\mathrm{AC}$ breakdown experiments. At pressure of $300 \mathrm{kPa}$ and separation of $5 \mathrm{~mm}$ a slight but no strong synergism has been observed. Consequently, a high $\mathrm{N}_{2} \mathrm{O}$ fraction is beneficial for the $\mathrm{ES}$, but limited by the oxidizing power, considered acceptable in high voltage equipment. Mixtures of $20 \%$ of $\mathrm{N}_{2} \mathrm{O}$ with inert buffer gases $\mathrm{N}_{2}$ or $\mathrm{CO}_{2}$ show an $\mathrm{ES} 16 \%$ to $22 \%$ above that of synthetic air. As the $O P$ of $\mathrm{N}_{2} \mathrm{O}$ is lower than of $\mathrm{O}_{2}$, the $\mathrm{N}_{2} \mathrm{O}$ fraction can be increased further up to $\mathrm{N}_{2} \mathrm{O} / \mathrm{CO}_{2} 49.1 / 50.9$ showing an ES $35 \%$ higher than synthetic air, and $45 \%$ of $\mathrm{SF}_{6}$.

For the design of a possible mixture for application, real GIS arrangements with operational pressures under $\mathrm{AC}$ and impulse voltage stress should be investigated.

In case of an application, $\mathrm{N}_{2} \mathrm{O}$ concentration around the equipment would have to be monitored to avoid concentrations causing even smallest anesthetic effects $(>6 \%)$, and to follow the exposure limits directions.

\section{ACKNOWLEDGMENT}

This work is financially supported by GE Grid (Switzerland) GmbH, Pfiffner Technologie AG, Hitachi ABB Power Grids, Switzerland Ltd and Siemens AG.

\section{REFERENCES}

[1] Linde-Group, "Datasheet Nitrous Oxide N2O", 2017, Available: http://www.linde-healthcare.at/de/images/N2O 10021720DE tcm549402333.pdf

[2] G. Parbrook,"The levels of nitrous oxide analgesia", Brit. J. Anaesth. 39, 974, 1967.

[3] G. Biasutti, "Neue Isoliergase fuer gekapselte Hochspannungsanlagen," $\mathrm{PhD}$ dissertation, ETH Zurich, 1985.

[4] G. Myhre et al, "Anthropogenic and Natural Radiative Forcing," Phys. Sci. Basis. Contrib. Work. Gr. Ito Fifth Assess. Rep. Intergov. Panel Clim. Chang. (IPCC), 2013, pp. 659-740.

[5] J. S. Daniel et al, "Scientific Assessment of ozone Depletion: 2010," World Meteorol. Organ., Glob. Ozon. Res. Mon. Pro., 2011, no. 52.

[6] G. Kirtman et al, "Near-term Climate Change: Projections and Predictability," Clim. Chang. 2013 Phys. Sci. Basis. Contrib. Work. Gr. I to Fifth Assess. Rep. Intergov. Panel Clim. Chang. (IPCC), 2013, pp. $953-$ 1028.

[7] M. Rabie and C. M. Franck, "Comparison of gases for electrical insulation: Fundamental concepts,", " IEEE Trans. Electr. Insul., vol. 25, no. 2, pp. 649-656, April 2018.

[8] A. Chachereau, M. Rabie, and C. M. Franck, "Electron swarm parameters of the hydrofluoroolefine HFO1234ze," Plasma Sourc. Sci. Technol., vol. 25 , no. 4, p. $045005,2016$.

[9] G. Biasutti and W. Zaengl, "Neue Isoliergase fuer die Hochspannungstechnik - Untersuchungen im homogenen Feld," Bull. de l'Assoc. sui. electr., vol. 74, no.3, pp. 140-147, 1983.

[10] M. Akbar and N. H. Malik, "Electrical breakdown of N20-SF6, N2O$\mathrm{CCl} 2 \mathrm{~F} 2$ and N20-C02 gas mixtures," IEEE Trans. Electr. Insul., vol. 20, no. 3, pp. 581-585, 1985.

[11] J. Dutton, F. M. Harris, and D. B. Hughes, "Electrical breakdown of nitrous oxide," Proc. Inst. Electr. Eng., vol. 120, no. 8, p. 941, 1973.

[12] S. R. Hunter and L. G. Christophorou, "Pressure-dependent electron attachment and breakdown strengths of unary gases and synergism of binary gas mixtures: A relationship," J. Appl. Phys., vol. 57, no. 9, pp. $4377-4385,1985$

[13] A. Hoesl et al, "Measurement and modeling of electron and anion kinetics in N2O discharges," J. Phys. D. Appl. Phys., vol. 53, no. 13, 2020.

[14] S. Dupljanin et al, "Transport coefficients and cross sections for electrons in N2O and N2O/N2 mixtures," Plasma Sour. Sci. Technol., vol. 19, no. 2, p. 025005, 2010.

[15] Gas cylinders - Gases and gas mixtures - Determination of fire potential and oxidizing ability for the selection of cylinder valve outlets, EN-ISO10156: 2017.

[16] N. Hayakawa et al, "Synergy effect in electrical insulation characteristics of N2O gas mixtures," IEEJ Trans. Power Energy, vol. 126, no. 11, pp. 1164-1170, 2006.

[17] H. Kojima et al, "Breakdown Characteristics of N2O Gas Mixtures for Quasiuniform Electric Field under Lightning Impulse Voltage," IEEE Trans. Dielectr. Electr. Insul., vol. 14, no. 6, pp. 1492-1497, 2007.

[18] W. Pfeiffer and D. Schoen, "Alternative gaseous insulation for GITL using N2O/N2 gas mixtures - dielectric performance of 20/80 \% N2O/N2 for VFT-stress," 5th Intern. Conf. Gas Discharges Their Appl., 2004, pp. 351-354.

[19] T. Hammer and T. Kishimoto, "Plasma-chemical decomposition of gas mixtures applied for electrical insulation," Int. J. Plasma Environ. Sci. Technol., vol. 8, no. 2, pp. 123-127, 2014.

[20] P. Haefliger and C. M. Franck, "Comparison of swarm and breakdown data in mixtures of nitrogen, carbon dioxide, argon and oxygen," J. Phys. D. Appl. Phys., vol. 52, no. 2, p. 25204, 2018.

[21] J. M. Truessel, H.-J. Weber, and C. M. Franck, "Safe and Automated Control of Experiments With a High Voltage Constuction Kit," 19th Int. Symp. High Volt. Eng., 2015, Pilsen, Czech Republic, August, 23 - 28, pp. 23-28, 2015.

[22] H. Schmid and A. Huber, "Measuring a Small Number of Samples, and the 3v Fallacy: Shedding Light on Confidence and Error Intervals," IEEE Sol.-St. Circ. Mag., vol. 6, no. 2, pp. 52-58, 2014. 
[23] M. Rabie and C. M. Franck, "Comparison of gases for electrical insulation: Fundamental concepts," IEEE Trans. Dielectr. Electr. Insul., vol. 25, no. 2, pp. 649-656, Apr. 2018.

[24] P. Haefliger, "Electric strength of N2, O2, CO2, Ar mixtures based on swarm and breakdown," PhD dissertation, ETH Zurich, 2018.

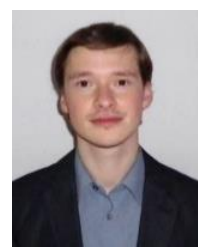

Juriy Pachin received the M.Sc. degree in electrical engineering and information technology from Technical University of Munich, Germany, in 2015. In 2016 he joined the High Voltage Laboratory, ETH Zurich, Switzerland, currently investigating discharge mechanisms in environmental friendly insulation gas mixtures.

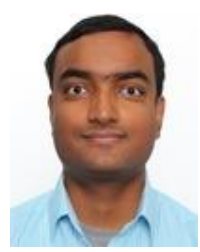

Siddharth Kumar received the M.Sc. degree from Delft University of Technology, The Netherlands, in 2016. Since 2017, he is a Ph.D. researcher in the Electrical Energy Systems group at Eindhoven University of Technology, Netherlands. His research interests are high voltage engineering, applications of pulsed power technologies and renewable energy technologies.

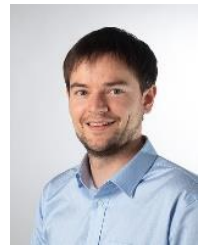

Andreas Hösl received his master degree in physics at the Ludwig Maximilians Universität München in 2013. He was awarded a Ph.D. for his thesis on electron detachment from anions formed in discharges in 2020 from the ETH Zurich.

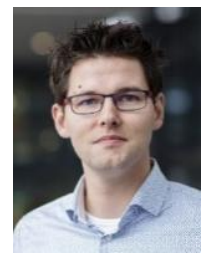

Tom Huiskamp received his M.Sc. degree (with honors) and $\mathrm{Ph} . \mathrm{D}$. degree (with honors) in electrical engineering from the Eindhoven University of Technology (TU/e), Eindhoven, The Netherlands, in 2011 and 2015, respectively. He was a Ph.D. Researcher with the Electrical Energy Systems Group, TU/e, where he was involved in nanosecond pulsed power-induced corona plasmas $\mathrm{He}$ is currently an Assistant Professor with TU/e. His current research interests include flexible, adjustable parameter (sub) nanosecond (solid-state) pulse source development and their application to transient plasmas for air purification and plasma-activated water generation applications.

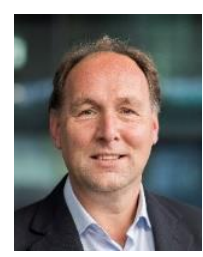

A.J.M. Pemen received the Ph.D. degree in electrical engineering from the Eindhoven University of Technology, Eindhoven, The Netherlands, in 2000. He is currently a Professor and the Chair with the Electrical Energy Systems Group, Eindhoven University of Technology, Eindhoven, The Netherlands, where he leads research on smart grids, power grid components, power quality and electromagnetic compatibility, and pulsed power technology.

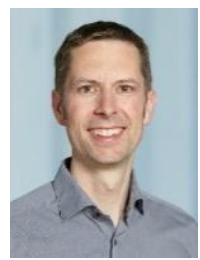

Christian M. Franck (M04-SM11) received a diploma in physics from the University of Kiel, Germany in 1999 and the Ph.D. degree in physics from the University of Greifswald, Germany in 2003. He was with the Swiss corporate research center of ABB during 2003-2009 as a Scientist and Group Leader for gas circuit breakers and high voltage systems. Currently, he is Full Professor for High Voltage Technology at ETH Zurich, Switzerland. His main research interests are in the area of gaseous insulation systems and equipment for HVDC. 